\title{
O conceito de região discursiva e a sua relevância para os Estudos da Tradução
}

\section{Vanessa Lopes Lourenço Hanes ${ }^{1}$}

Abstract: The objective of this article is to present the concept of speech region and its translation into Brazilian Portuguese: região discursiva. First the steps taken to translate the term are explained, as well as the translation options considered. Afterwards some comments are made concerning the relevance of the term as a concept in Translation Studies, particularly relating to dialect translation.

Keywords: speech region; região discursiva; dialect translation; Translation Studies.

Resumo: 0 presente artigo visa apresentar o conceito de speech region e a sua tradução para o português brasileiro: região discursiva. Inicialmente, são apresentados o caminho percorrido para a tradução do termo e as opções tradutórias consideradas. Em um segundo momento são tecidas colocações sobre qual a relevância do termo em questão enquanto conceito para os Estudos da Tradução, em especial para a tradução de dialetos.

Palavras-chave: speech region; região discursiva; tradução de dialetos; Estudos da Tradução.

\section{Introdução}

Nos últimos anos, tenho me proposto a trabalhar com uma temática que ainda é, até onde tenho observado, pouco explorada no universo acadêmico brasileiro: a tradução de dialetos. Meu foco tem sido a tradução do

1 Doutoranda em Estudos da Tradução, Universidade Federal de Santa Catarina. Email: vanessahanes@gmail.com. 
HANES, V. L. L. O conceito de região discursiva e a sua relevância para os Estudos da Tradução

dialeto inglês sulista norte-americano e de suas diversas subvariedades no contexto do Brasil.

Devido à relativa novidade deste objeto de estudo, tenho me deparado nesta caminhada com alguns conceitos também novos e, em algumas ocasiões, inovadores, graças ao seu recente surgimento ou ao seu desconhecimento por linguistas brasileiros. Este foi o caso do conceito de speech region, que optei por traduzir como região discursiva, devido a motivos a serem explanados mais a frente.

Segundo recenseamento que realizei, há atualmente dois conceitos possíveis utilizados para o termo speech region entre linguistas norteamericanos e de fala inglesa em geral. O primeiro deles, mais tradicional, está ligado à área da neurolinguística, e se atém às regiões cerebrais responsáveis pela fala. Este é o contexto em que o termo é utilizado por DALY e HESTER (1973), do Departamento de Linguística da University of Texas: "The hemispheres have both morphological and functional asymmetries. (...) asymmetries exist in the temporal speech region". Esta abordagem do termo, no entanto, não será englobada no presente artigo.

0 outro conceito denominado de speech region, que tomou vulto mais recentemente, e sobre o qual pretendo discorrer aqui, está ligado à geolinguística e à sociolinguística, e se refere ao espaço geográfico em que um determinado tipo de discurso ocorre. Sua utilização se dá em especial por linguistas que lidam diretamente com questões dialetais, na tentativa de estabelecer limites físicos para os fenômenos linguísticos com os quais atuam. Entre tais profissionais podem ser citados Balley e TILleRY (1996), Wolfram (2003) e J OHNSON e Montgomery (2007). Todos estes autores mencionam 0 termo speech region diretamente em seus estudos.

Assim, este artigo se dividirá em dois momentos: primeiramente serão descritos os passos percorridos para o estabelecimento da tradução do termo região discursiva em português brasileiro; a seguir, o termo em apreço será situado no âmbito dos estudos da tradução. 


\section{A tradução do termo speech region: por que região discursiva?}

Em meu estudo de dialetos norte-americanos, tenho encontrado frequentemente casos onde ocorre o uso do conceito de speech region e, por isto, fez-se necessário procurar um termo existente na língua portuguesa que exprimisse o mesmo sentido do termo usado nos Estados Unidos, para que pudesse ser utilizado como tradução em citações apresentadas em artigos e em minha dissertação de mestrado, defendida recentemente. Para isso, optei por consultar linguistas renomados que pudessem me auxiliar na descoberta de um termo já cunhado que descrevesse o conceito com propriedade. Porém, minhas buscas foram infrutíferas, já que nenhum dos professores universitários procurados pôde oferecer uma solução a esta questão tradutória. Embora ficasse claro o conceito do termo em inglês, tais profissionais não conseguiram encontrar um conceito semelhante em português. Eles foram unânimes em sugerir que eu buscasse elaborar uma tradução plausível para o termo em debate.

A partir daí, passei então a procurar alternativas. A primeira opção que me ocorreu foi o uso de "região linguística", pois este termo, embora segundo recenseamento que empreendi ainda não tenha sido definido formalmente, já é utilizado em alguns estudos linguísticos brasileiros, como no caso daquele conduzido por CARdoso (1999). Porém, em uma segunda análise, esta expressão pareceu inadequada para a tradução, devido a dois motivos. 0 primeiro é que na língua inglesa existe o termo linguistic region, e, sendo assim, isto determina que o conceito de speech region não teria o mesmo sentido, já que obviamente tem um nome diferente; desta forma, consequentemente também não seria o mesmo que região linguística, uma tradução literal de linguistic region. O segundo motivo,que de certa maneira surgiu a partir da primeira oposição já apresentada, foi que a expressão 
HANES, V. L. L. O conceito de região discursiva e a sua relevância para os Estudos da Tradução

"região linguística" parece extremamente abrangente, já que o próprio conceito de linguística engloba um amplo leque de possibilidades enquanto objeto de estudo.

Seguindo este raciocínio, pareceu relevante procurar o que é específico do termo speech region, para assim encontrar uma tradução cabível. 0 item lexical speech tem como foco a fala. E fica claro nos estudos desenvolvidos por linguistas norte-americanos que region está se referindo a regiões geográficas. Assim, a speech region seria uma "região de fala". Porém, no português tal tradução parece não funcionar de modo satisfatório, já que normalmente quando se lê esta expressão parece ser necessário adicionar um complemento a ela, por exemplo, "região de fala espanhola", "região de fala francesa", e assim por diante, devido a questões de colocação. Passei então a me perguntar qual seria um substituto plausível para "fala", que expressasse seu significado. Foi aí que surgiu a ideia da utilização de "discurso" para a tradução.

Segundo DuBols et al. (2004), "discurso é a linguagem posta em ação, a língua assumida pelo falante". Estes autores ainda colocam após esta definição que discurso é um sinônimo de fala, o que mostrou claramente a sua relevância para a utilização. Desta forma, optei pelo uso da tradução região discursiva, pois essa parece englobar e transmitir com propriedade a compreensão do termo no âmbito em que é utilizado em seu contexto original, e também em meus estudos desenvolvidos no Brasil.

Sendo assim, nos contextos aqui apresentados, uma região discursiva se refere a um território geográfico no qual determinado tipo de discurso é utilizado. Discurso é entendido enquanto um encadeamento de palavras que segue determinadas regras gramaticais e ordem que garantem sua compreensão por outros suj eitos do mesmo grupo no qual o falante se insere. No caso de minha pesquisa, a região discursiva seria o sul dos Estados Unidos, na qual predomina o uso do dialeto inglês sulista norte-americano. 


\section{Região discursiva versus Estudos da}

\section{Tradução}

Diante das considerações apresentadas anteriormente, já começa a se delinear qual seria a relevância da compreensão de região discursiva para os estudiosos das áreas da linguística e da tradução.

Talvez, sua aplicabilidade para a linguística fique mais clara, já que é nesta mesma área e em suas áreas adjacentes que o termo vem sendo empregado em seu contexto original nos Estados Unidos. Assim, aqueles que lidam com a sociolinguística podem se valer de um termo que descreva a região geográfica em que determinado grupo social e de fala específica se insere. E a geolinguística pode fazer uso do conceito para o mesmo fim.

Porém, e para os estudos da tradução, qual seria o uso desta terminologia? Em minha opinião, cada dia mais as pesquisas desenvolvidas nos estudos da tradução estão buscando contemplar aquilo que EvEN-ZOHAR (1990) chama de polissistemas, definido por este autor da seguinte maneira:

\section{[...] the term polysystem is more than just a terminological convention. Its purpose is to make explicit the conception of a system as dynamic and heterogeneous [...] It thus emphasizes the multiplicity of intersections and hence the greater complexity of structuredness involved.}

Assim, uma das intersecções do polissistema de partida seria a região discursiva em que determinada obra a ser traduzida ou cuja tradução está sendo analisada se insere. A relevância da consideração da região discursiva como parte do polissistema fica clara ao compreender-se que uma obra é permeada por elementos geográficos, sociais e culturais presentes, mas, ao mesmo tempo, externos a ela, que a determinam e influenciam. Em uma análise macroestrutural de qualquer obra, a região discursiva pode 
HANES, V. L. L. O conceito de região discursiva e a sua relevância para os Estudos da Tradução

desempenhar papel fundamental para o estabelecimento de características específicas, ajudando a desvendar a complexa estrutura envolvida em sua produção.

A abordagem do conceito aqui descrito tem ainda mais importância ao considerar os estudos que, ao exemplo do que tenho feito, lidam com a tradução de dialetos. Apesar de ser ainda uma área pouco explorada, vejo que nos últimos anos a tendência de lidar com a tradução de variações linguísticas regionais tem aumentado, e diversas discussões têm sido iniciadas neste sentido. Há vários alunos de pós-graduações por todo o Brasil que têm buscado lidar com diferentes dialetos de diferentes localidades. E, neste contexto, cada dia mais os estudiosos da tradução precisarão focalizar a área em que tal fala é presente, pois sem contextualização deixa-se de explorar um aspecto único de cada fenômeno linguístico trabalhado.

Sendo assim, a proposta aqui não é que a região discursiva seja vista somente como um conceito em si mesmo, um termo vazio. A ideia é que, a partir da compreensão do significado deste termo e de sua relevância para 0 polissistema em que a obra se insere, as pesquisas venham se dispor a dispensar atenção redobrada para o contexto dialetal.

Entendo que não é inédita a proposta de considerar o contexto de partida de uma obra, mas vejo urgência em sugerir que, no contexto da tradução de dialetos, a especificação deste contexto, ou seja, da região discursiva em que a obra se situa geográfica e historicamente, pode inclusive influenciar diretamente o projeto de tradução a ser desenvolvido, quer por aquele que explora a região discursiva em debate ou por outro pesquisador ou profissional de tradução que futuramente se aproprie de seus dados para a elaboração de uma tradução. Esta visão mais ampla do texto a ser traduzido enquanto parte intrínseca de uma região discursiva poderá informar as decisões tradutórias frente ao dialeto, e quem sabe futuramente levar a uma quebra do paradigma hoje instaurado no Brasil de que dialeto traduzido para o português em linhas gerais costuma ser traduzido segundo a norma culta, ou 
HANES, V. L. L. O conceito de região discursiva e a sua relevância para os Estudos da Tradução

seja, o dialeto do texto de partida é suprimido. Segundo MILTON (2002), há uma visão conservadora no Brasil, na qual o dialeto não tem espaço; a prioridade é dada à norma culta.

Creio que, no âmbito dos estudos da tradução, a compreensão do conceito de região discursiva - e em particular da região discursiva na qual foi escrito o texto de partida tido como objeto de estudo de cada pesquisador pode incitar a busca por uma tradução que contemple, também no texto de chegada, uma região discursiva que tenha semelhanças com a traduzida, enriquecendo o processo tradutório como um todo. Esta seria, em síntese, a utilização almejada para o conceito de região discursiva, unindo a teoria com a prática tradutória.

\section{Conclusão}

Ao apresentar o caminho percorrido para a tradução do termo região discursiva, o presente estudo expôs um modelo que possivelmente poderá ser útil também para futuras traduções de termos ainda não cunhados no Brasil.

0 conceito de região discursiva parece ter potencial para enriquecer 0 âmbito dos estudos da tradução, a exemplo do que já tem feito com a área da linguística em seu contexto original. Espero confirmar ou rechaçar sua aplicabilidade durante meu aprofundamento na tradução de dialetos, área em que creio que o conceito será de maior utilidade.

\section{Referências bibliográficas}

Bailey, G.; TIllery, J. The Persistence of Southern American English. J ournal of English Linguistics, v. 24, n. 4, 1996, p. 308-321. 
HANES, V. L. L. O conceito de região discursiva e a sua relevância para os Estudos da Tradução

CARDoso, S. A. M. A Dialectologia no Brasil: perspectivas. DELTA, v. 15, edição especial, 1999, p. 233-255.

Daly, D. M.; HeSTeR, T. R. Logic and Cerebral Hemispheric Interaction. MidAmerica Linguistics Conference, 1973, p. 158.

DuBols, J. Discurso. In: Dicionário de Linguística. São Paulo, Editora Cultrix, 2004, p. 192.

Even-Zohar, I. Polysystem theory. Poetics Today, v. 11, n. 1, 1990, p. 12.

J OHNSON, E.; MONTGOMERY, M. Language in the south. In:

(Ed.). The New encyclopedia of southern culture. Chapel Hill, The University of North Carolina Press, 2007, p. 1-27.

MILTON, J. O Clube do livro e a tradução. Bauru: EDUSC, 2002.

WolfRAm, W. Language variation in the American south: an introduction. American Speech, v. 78, n. 2, 2003, p. 123-129. 